\title{
HUBUNGAN KUANTITATIF FITOPLANKTON DAN ZOOPLANKTON PERAIRAN SUAKA PERIKANAN GILI RANGGO TELUK SEREWE LOMBOK TIMUR
}

\author{
Lalu Japa $^{(1)}$, Suripto $^{(2)}$, dan I Gde Mertha ${ }^{(1)}$ \\ (1). Program Studi Biologi FMIPA Universitas Mataram, (2). Program Studi Pendidikan Biologi \\ PMIPA FKIP Universitas Mataram
}

\begin{abstract}
ABSTRAK
Empat belas sampel air laut diamati komunitas planktonnya. Sampel diambil di kawasan perairan suaka perikanan Gili Ranggo Teluk Serewe Lombok Timur, menggunakan jaring plankton bermata jaring 20 mikron. Pengamatan dan identifikasi spesies plankton dilaksanakan di Laboratorium Biologi Dasar UPT-MIPA Universitas Mataram. Kepadatan setiap jenis fitoplankton dan zooplankton ditentukan berdasarkan jumlah individu per liter air. Indeks keanekaragaman jenis fitoplankton dan zooplankton ditentukan berdasarkan "Indeks Shannon-Wienner". Selanjutnya, hubungan kuantitatif antara fitoplankton dan zooplankton ditentukan dengan menggunakan "Korelasi Jenjang Spearman". Total plankton teridentifikasi adalah 123 spesies meliputi 82 spesies fitoplankton dan 41 spesies zooplankton. Komunitas fitoplankton didominasi oleh spesies dari famili Bacillariophyceae (diatom), yaitu sebanyak 75 spesies. Tujuh spesies lainnya adalah anggota dari family Dinophyceae (dinoflagellata). Sedangkan komunitas zooplankton di perairan suaka perikanan Gili Ranggo Teluk Serewe Lombok Timur didominasi oleh spesies dari genus Tintinnopsis. Nilai indeks keanekaragaman jenis fitoplankton dan zooplankton termasuk dalam kategori keanekaragaman sedang. Hubungan kuantitatif fitoplankton dengan zooplankton pada taraf signifikansi 5\% dengan tujuh pasang jenjang, diperoleh hasil $r_{s \text { Hitung }}$ lebih kecil dari $r_{s}$ Tabel $(0,643<$ $0,857)$, artinya bahwa tidak terdapat korelasi positif antara fitoplankton dan zooplankton.
\end{abstract}

Kata-kata kunci: kuantitatif, fitoplankton, zooplankton, suaka perikanan

\begin{abstract}
Fourteen of $50 \mathrm{ml}$ volume bottle plankton net collecting samples were observed for the community of plankton (phytoplankton and zooplankton) of the fish sanctuary of Gili Ranggo (Serewe Bay) east Lombok. Samples observation and plankton identification were done at the Laboratory of Biology, UPT-MIPA University of Mataram. Density or abundant of each plankton species was determined based on the number of individual per liter. Shannon-Wienner Diversity Index was applied for determining the species diversity index. Furthermore, the "Spearman Correlation" was also applied for analyzing the quantitative correlation of phytoplankton and zooplankton. Total of 50 genera containing 123 species of plankton were fully identified. This study fully identified of 82 species of phytoplankton, the members of both Dynophyceae (dinoflagellates) and Bacillariophyceae (diatom) families, and 41 species of zooplankton. The fish sanctuary of Gili Ranggo, Serewe Bay was dominated by the member of Bacillariophyceae family. The 41 species of zooplankton is dominated by the species of the genus Tintinnopsis. Both phytoplankton and zooplankton communities have a high species diversity index category. Quantitative correlation of phytoplankton and zooplankton at a seven pair and significant of $5 \%$, is $r_{s}$ count less than $r_{s}$ Table $(0.643<0.857)$. This means, there was no possitive correlation between the present of phytoplankton and zooplankton communities.
\end{abstract}

Key Words: quantitative, phytoplankton, zooplankton, fish sanctuary 


\section{PENDAHULUAN}

$\mathrm{I}$ ndonesia sebagai negara kepulauan memiliki garis pantai sekitar $81.000 \mathrm{~km}$ panjangnya (Resosoedarmo et al., 1992, Dahuri, 2000), dengan luas perairan lautnya adalah $67 \%$ dari total wilayah Indonesia (Noor, 2000). Kawasan perairan laut yang sedemikian luasnya ini merupakan potensi sumber daya alam yang tak ternilai harga, tetapi sekaligus menciptakan tantangan yang sangat besar bagi pengelolaannya. Suatu fenomena yang tak terelakkan, bahwa disekitar pantai sepanjang itu dan laut seluas itu merupakan tempat terkonsentrasinya berbagai kegiatan dan aktivitas sebagian besar penduduk Indonesia. Pengelolaan prikanan dapat dipastikan sebagai bentuk aktivitas yang dominan dan dilakukan oleh sebagian besar penduduk.

Terkait dengan pengelolaan kawasan pantai dan laut, maka pada tahun 2001 melalui Proyek Co-Fish telah berhasil dibentuk 3 (tiga) kawasan suaka perikanan (Fish Sanctuaries) di wilayah Kabupaten Lombok Timur. Ketiga suaka perikanan tersebut adalah Suaka Perikanan Gili Ranggo di Teluk Serewe, Suaka Perikanan Sapak Kokok di Teluk Ekas dan Suaka Perikanan Gusoh Sandak di Teluk Jukung. Dari ketiga suaka perikanan ini, Suaka Perikanan Gili Ranggo, Teluk Serewe memiliki karakteristik yang paling berbeda. Kawasan suaka perikanan ini memiliki areal hutan mangrove yang cukup luas, juga memiliki areal pada lamun yang lebat dan luas. Disamping itu, di suaka perikanan tersebut juga merupakan temapt bermuaranya kali dan daratan sekitarnya berupa bukit yang dijadikan sebagai daerah lokasi tujun transmigrasi.

Potensi sumberdaya alam hayati suatu kawasan atau eksosistem perairan sangat ditentukan oleh produktivitas primer plankton (zooplankton dan fitoplankton). Zooplankton sebagai organisme konsumen pertama sangat bergantung pada fitoplankton sebagai produsen pertama. Arinardi (1978) menyimpulan walaupun jumlah fitoplankton sangat tinggi tetapi jumlah zooplankton bisa sangat rendah dan sebaliknya. Ini berarti, bahwa komunitas zooplankton dan fitoplankton dipernagruhi oleh banyak faktor, tidak hanya faktor biologi tetapi juga faktor kimia dan fisika perairan. Selanjutnya, fitoplankton sebagai organisme uniseluler air sangat peka dengan perubahan ekosistem perairan, yang tercermin dari kualitas airnya. Keberadaan komunitas fitoplankton juga merupakan kelompok organisme perairan yang paling banyak dilaporkan sebagai tolak ukur dalam mengontrol kualitas dan produktivitas suatu perairan.

Kemelimpahan fitoplankton di suatu perairan menggambarkan produktivitas primer ekosistem perairan tersebut. Fitoplankton sebagai komponen dasar jaring-jaring makanan ekosistem perairan merupakan sumber makanan utama organisme periaran terutama zooplankton yang kemudian dimakan oleh ikan-ikan kecil. Ikan-ikan kecil ini selanjutnya akan dimangsa oleh ikan-ikan yang lebih besar dan seterusnya sampai kepada predator lainnya, sehingga memungkinkan terjadinya aliran energi dan materi sampai ke jenjang profit yang lebih tinggi, bahkan sampai ke puncak profit, manusia. Bisa dibanyangkan, bahwa kehilangan fitoplankton sampai $5 \quad \% \quad$ dapat menyebabkan menurunnya produksi ikan sampai 70.000 ton setiap tahun (Harder et al., 1995). Berkenaan dengan itu, dan managemen qualitas air merupakan kebijakan penting untuk aspek lingkungan dan sumber alam (Hall dan Smol, 1999), yang memerlukan perhatian secara khusus agar dapat menentukan kebijakan pengelolaan yang optimal untuk kesejahteraan dengan prinsip berkelanjutan dan ramah lingkungan.

Sampai saat ini tingkat aspirasi masyarakat, tak terkecuali masyarakat 
intelektual terhadap keberadaan kelompok organisme ini di tengah-tengah kehidupan masih sangat rendah, sehingga organisme yang tak kasap mata ini nyaris tak pernah dijamah dalam skop pengertian ilmiah. Penelitian mengenai hubungan antara zooplankton dan fitoplankton sangat terbatas khususnya di Indonesia, dan tidak pernah dilakukan di perairan pulau Lombok. Penelitian dan identifikasi spesies-spesies fitoplankton perairan Indonesia belum kedengaran dilaporkan, kecuali oleh Allen dan Cupp (1935) untuk sebagian kecil daerah perairan Jawa, Sumatera dan Kalimantan dan Hustedt (1939) untuk kawasan yang sama ditambah Bali. Penelitian terbaru untuk satu titik di pulau Lombok dilaporkan oleh Japa (2000). Tidak menutup kemungkinan, sebagaimana di negara-negara di belahan bumi lainnya, spesies-spesies yang potensial beracun dan mengalami blooming sangat mungkin dijumpai di perairan Indonesia, termasuk Lombok. Penelitian ini dimaksudkan untuk menentukan hubungan kualitatif antara komunitas zooplankton dan fitoplankton di perairan Gili Ranggo, teluk Serewe Lombok Timur. Identifikai jenis zooplankton dan fitoplankton serta keaneragaman dan kemelimphan masing-masing jenis adalah dasar mutlak penelitian. Oleh karena diperlukan 2 (dua) sub-judul yang secara khusus mengkaji lebih detil komunitas zooplankton dan fitoplanton. Kedua subjudul tersebut sebagai judul skripsi 2 (dua) orang mahasiswa Program Studi Pendidikan Biologi FKIP Universitas Mataram.

Keberadaan potensi sumberdaya alam kawasan Suaka Perikanan Gili Ranggo Teluk Serewe Lombok Timur perlu di kontrol sejak awal keberadaan suaka perikanan tersebut. Data awal mengenai potensi sumberdaya alam hayati kawasan tersebut akan sangat besar maknanya terhadap aktivitas pengontrolan selanjutnya. Setahun sejak terbentuknya kawasan tersebut dilakukan pengontrolan atau monitoring oleh tim dari Yayan Laut Biru
(YLB) terbatas pada potensi hutan mangrove dan padang lamun termasuk potensi kepiting dan ikan kawasan tersebut. Kontrol terhadap komunitas zooplankton dan fitoplankton belum pernah dilakukan. Oleh karena itu, penelitian ini akan mencoba mengungkap potensi sumberdaya alam hayati zooplankton dan fitoplankton termasuk hubungan secara kualitatif kedua sumberdaya alam ini. Kawasan perairan Suaka Perikanan Gili Ranggo Teluk Serewe dipilih sebagai obyek penelitian, karena kondisi perairan kawasan tersebut cendrung dipengaruhi oleh aktivitas di daratan, sejak kawasan tersebut dekat dengan pemukiman penduduk dan lokasi transmigrasi, tempat bermuaranya kali besar serta memiliki kawasan hutan mangrove dan padang lamun yang cukup luas.

\section{MATERIAL DAN METODE}

Pengambilan sampel air laut dilakukan pada tanggal 9 September 2003. Sampel air laut sebanyak $50 \mathrm{ml}$ diambil dua kali pada setiap titik pengambilan sampel dengan menggunakan jaring plankton dengan mata jaring berukuran $20 \mu \mathrm{m}$. Setiap sampel diawet dengan formalin $37 \%$, dan konsentrasi pengawetan sampel menjadi 4\%. Pengamatan dan identifikasi spesies fitoplankton dilaksanakan di Laboratorium Biologi PMIPA FKIP Universitas Mataram. Pengmabilan gambar bebarapa sepsies yang dianggap penting akan dilaksanakan di Laboratorium Biologi Dasar UPT-MIPA Universitas Mataram. Identifikasi spesies dilakukan secara morfologi (Hall dan Smol, 1999) berdasarkan sumber-sumber yang ditulis oleh Lebour, (1930); Allen and Cupp, (1935); Simonsen, (1974); Belcher and Swale, (1976); Taylor, (1976); Vinyard, (1979); Navarro, (1982); Yamji (1984); dan Hernandez-Becerril, (1996). Data kimiafisika lainnya, seperti salinitas, suhu, $\mathrm{pH}$ dan kejernihan air diukur langsung di lapangan ketika pengambilan sampel.

Data dianalisis dengan Bray Curtis Cluster Analysis untuk membuat 
dendogram yang mengambarkan tingkat kesamaan dan perbedaan masing-masing titik pengambilan sampel berdasarkan data kemelimpahan setiap jenis komunitas fitoplankton dan zooplankton. Analisis data komunitas fitoplankton dan zooplankton dititik beratkan pada penghitungan Kepadatan Relatif (DR), Frequensi Relatif (FR) dan Nilai Penting (NP) setiap jenis yang jumlahnya dikonversikan dalam setiap liter air. Jenis dengan NP paling tinggi menunjukkan, bahwa jenis tersebut relatif paling melimpah di komunitas tersebut (Michael, 1984). Selanjutnya, nilai penting suatu jenis dihitung dengan menjumlahkan harga-harga relatif jenis tersebut. Kepadatan setiap jenis fitoplankton dan zooplankton ditentukan berdasarkan jumlah individu per liter air. Perhitungan jumlah total plankton (fitplankton dan zooplankton) dalam 1 (satu) liter air dilakukan dengan menggunakan rumus menurut Romimohtarto dan Juwana (2001) yakni: Indeks keanekaragaman jenis fitoplankton dan zooplankton ditentukan berdasarkan "Indeks Shannon-Wienner (H')" dengan rumus menurut Cox (1976), Romimohtarto dan Juwana (2001), dan Barus (2002). Hubungan kuantitatif antara fitoplankton dan zooplankton ditentukan dengan menggunakan "Korelasi Jenjang Spearman" (Snedecor dan Cochran, 1989, Sprent, 1991).

\section{HASIL DAN PEMBAHASAN Hasil Penelitian}

Lokasi penelitian dibagi menjadi 7 stasiun. Tiga stasiun pertama berada di luar kawasan suaka perikanan. Posisi dan kondisi kimia-fisika masing-masing stasiun seperti disajikan dalam Tabel 1 berikut ini.

Tabel 1. Posisi dan data kimia-fisika masing-masing stasiun penelitian

\begin{tabular}{|c|c|c|c|c|c|c|c|}
\hline \multirow{2}{*}{ No. } & Stasiun & \multicolumn{2}{|c|}{ Posisi } & $\begin{array}{c}\text { Salinitas } \\
(\%)\end{array}$ & $\begin{array}{c}\text { Suhu } \\
\left({ }^{\circ} \mathrm{C}\right)\end{array}$ & $\begin{array}{c}\text { pH } \\
\text { Kecerah } \\
\text { an (m) }\end{array}$ \\
\cline { 3 - 6 } 1. & I & $08^{\circ} .54^{\prime} .528^{\prime \prime}$ & $116^{\circ} .30^{\prime} .434^{\prime \prime}$ & 34 & 25 & 7,7 & 12 \\
2. & II & $08^{\circ} .54^{\prime} .591^{\prime \prime}$ & $116^{\circ} .30^{\prime} .594^{\prime \prime}$ & 34 & 25 & 6,0 & 8 \\
3. & III & $08^{\circ} .54^{\prime} .546^{\prime \prime}$ & $116^{\circ} .30^{\prime} .880^{\prime \prime}$ & 34 & 23 & 5,9 & 8 \\
4. & IV & $08^{\circ} .54^{\prime} .253^{\prime \prime}$ & $116^{\circ} .30^{\prime} .800^{\prime \prime}$ & 34 & 23 & 6,0 & - \\
5. & V & $08^{\circ} .54^{\prime} .028^{\prime \prime}$ & $116^{\circ} .30^{\prime} .507^{\prime \prime}$ & 34 & 23 & 5,8 & 10 \\
6. & VI & $08^{\circ} .54^{\prime} .959^{\prime \prime}$ & $116^{\circ} .30^{\prime} .147^{\prime \prime}$ & 34 & 22 & 5,7 & - \\
7. & VII & $08^{\circ} .52^{\prime} .870^{\prime \prime}$ & $116^{\circ} .30^{\prime} .810^{\prime \prime}$ & 34 & 22 & 5,7 & - \\
\hline
\end{tabular}

Faktor kimia-fisika air suaka perikanan Teluk Serewe Lombok Timur, terutama $\mathrm{pH}$, suhu dan kecerahannya relatif bervariasi, kecuali salinitas yang konstan. Variasi suhu berkisar pada $22-25{ }^{\circ} \mathrm{C}$; $\mathrm{pH}$ : 5,7-7,7; dan kecerahan air antara $8 \mathrm{~m}$ sampai $12 \mathrm{~m}$ (Tabel 1).

Total plankton yang teridentifikasi sebanyak 123 spesies dengan perincian, 82 spesies adalah plankton nabati (fitoplankton) dan sisanya, 41 spesies adalah plankton hewani (zooplankton). Delapan puluh dua spesies fitoplankton ini terdiri dari 75 spesies adalah anggota dari klas Bacillariophyceae (diatom), dan anggota dari klas Dinophyta (dinoflagellata) hanya sebanyak 7 spesies.

Sebaran jumlah taksa baik fitoplankton dan zooplankton pada setiap stasiun cukup bervariasi. Jumlah taksa 
fitoplankton selalu lebih banyak daripada jumlah taksa zooplankton pada semua stasiun pengambilan sampel penelitian ini (Gambar 1). Fluktuasi jumlah taksa fitoplankton jauh lebih beragam dibanding fluktuasi jumlah taksa zooplankton. Bahkan jumlah taksa zooplankton di semua stasiun relatif stabil, tidak ada yang lebih menonjol antara stasiun satu dengan lainnya. Jumlah terbanyak taksa fitoplankton tercatat pada stasiun II dan paling sedikit tercatat pada stasiun I.

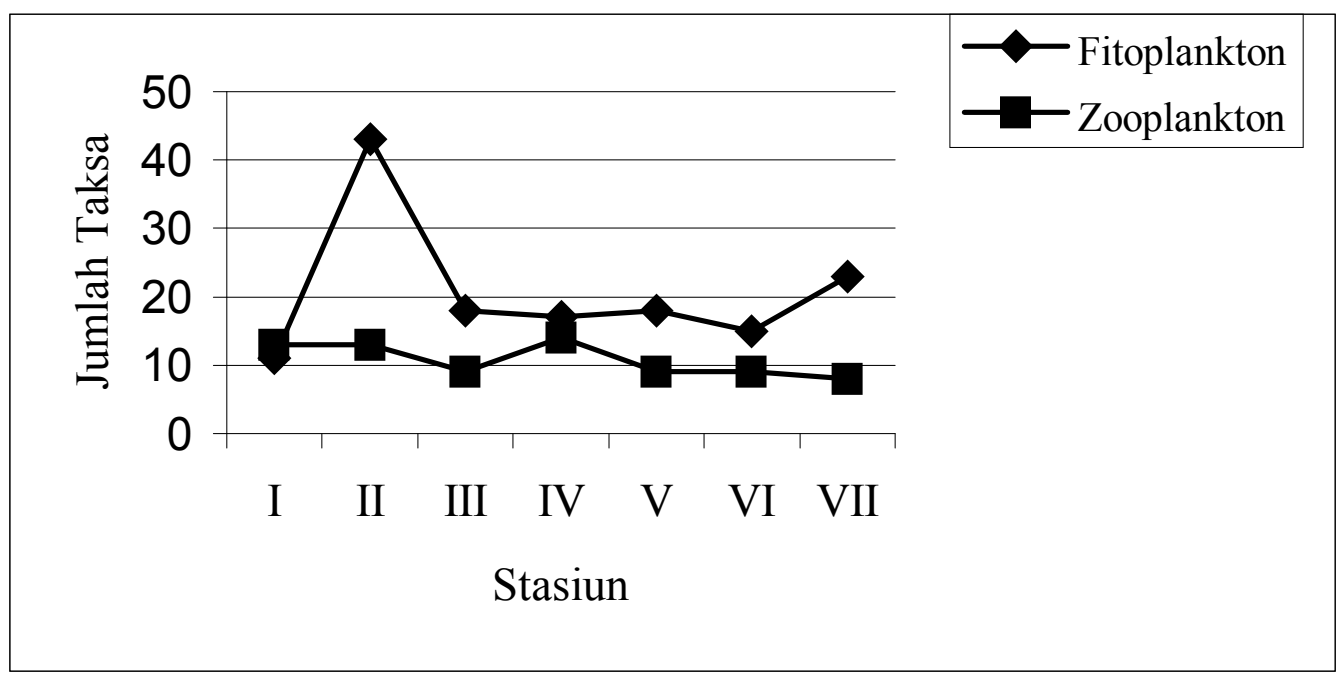

Gambar 1. Perbandingan proforsi jumlah taksa antara fitoplankton dan zooplankton pada masing-masing pengambilan sampel

Dalam perhitungan pada taraf signifikansi 5\%, diperoleh hasil $r_{S}$ Hitung lebih kecil dari $r_{s}$ Tabel $(0,643<0,857)$. Ini berarti, bahwa secara kuantitatif hubungan antara fitoplankton dan zooplankton di perairan suaka perikanan teluk Serewe Lombok Timur tidak ada. Dengan kata lain, komunitas fitoplankton tidak mempunyai pengaruh terhadap komunitas zooplankton.

Dari 82 spesies anggota dari komunitas fitoplankton yang teridentifikasi didominasi oleh anggota dari famili Bacillariophyceae (75 spesies). Sedangkan famili Dinophyceae diwakili oleh 7 spesies saja. Nilai indeks keanekaragaman jenis (H') fitoplankton adalah termasuk kategori sedang $\quad(3,937)$ Spesies-spesies Bacillariophyceae dengan kepadatan tinggi berturut-turut adalah Pseudo-nitzschia spp. (42,857 ind/L), Skeletonemma sp. (34,286 ind/L), N. longissima $(27,143 \mathrm{ind} / \mathrm{L})$, dan Navicula $\quad$ sp. $\quad(24,286$ ind/L). Tetapi berdasarkan nilai pentingnya (NP), maka urutan dominasinya adalah: $N$. longissima (NP: 12,661), Navicula sp. (NP: 9,213); Pseudo-nitzschia spp. (NP: 8,086\%); dan Skeletonemma sp. (NP: 4,632). Sedangkan dari famili Dinophyceae, 3 spesies yang memiliki kepadatan tinggi adalah Peridinium quinquecorne (32,857 ind/L), dengan dominasi (NP: 3,816); disusul oleh Prorocentrum micans $(11,429$ ind/L) dengan NP: 5,754; dan Protoperidinium sp. (8,571 ind/L), dengan NP: 5,751.

Komunitas zooplankton di perairan Suaka Perikanan Teluk Serewe Lombok Timur didominasi oleh spesies dari genus Tintinnopsis. Dari 41 spesies zooplankton yang teridentifikasi, 15 spesies merupakan anggota dari genus Tintinnopsis. Enam spesies anggota dari komunitas zooplankton yang teridentifikasi dengan kepadatan dan nilai penting (NP) tertinggi berturut-turut adalah Tintinnopsis anguistor (104,286 ind/L) dengan NP: 14,$096 ; T$. radix $(91,429$ 
ind/L), NP: 16,$369 ; \quad T$. tenuis $(45,714$ ind/L), NP: 7,032; T. karajacensis $(17,143$ ind/L), NP: 5,807; Acartia clausi $(17,143$ ind/L), NP: 6,959, T. japonica $(15,714$ ind/L), NP: 5,803. Nilai indeks keanekaragaman jenis (H') zooplankton juga termasuk dalam kategori keanekaragaman sedang $(2,542))$. Lima spesies merupakan zooplankton dengan kepadatan dan NP masuk dalam kategori tertinggi. Dengan kata lain, spesies dari genus Tintinnopsis merupakan yang paling dominan dari segi jumlah spesies, kepadatan dan nilai penting (NP). Selanjutnya dapat dikatakan, bahwa komunitas zooplankton di perairan Suaka Perikanan tersebut didominasi oleh zooplankton genus Tintinnopsis.
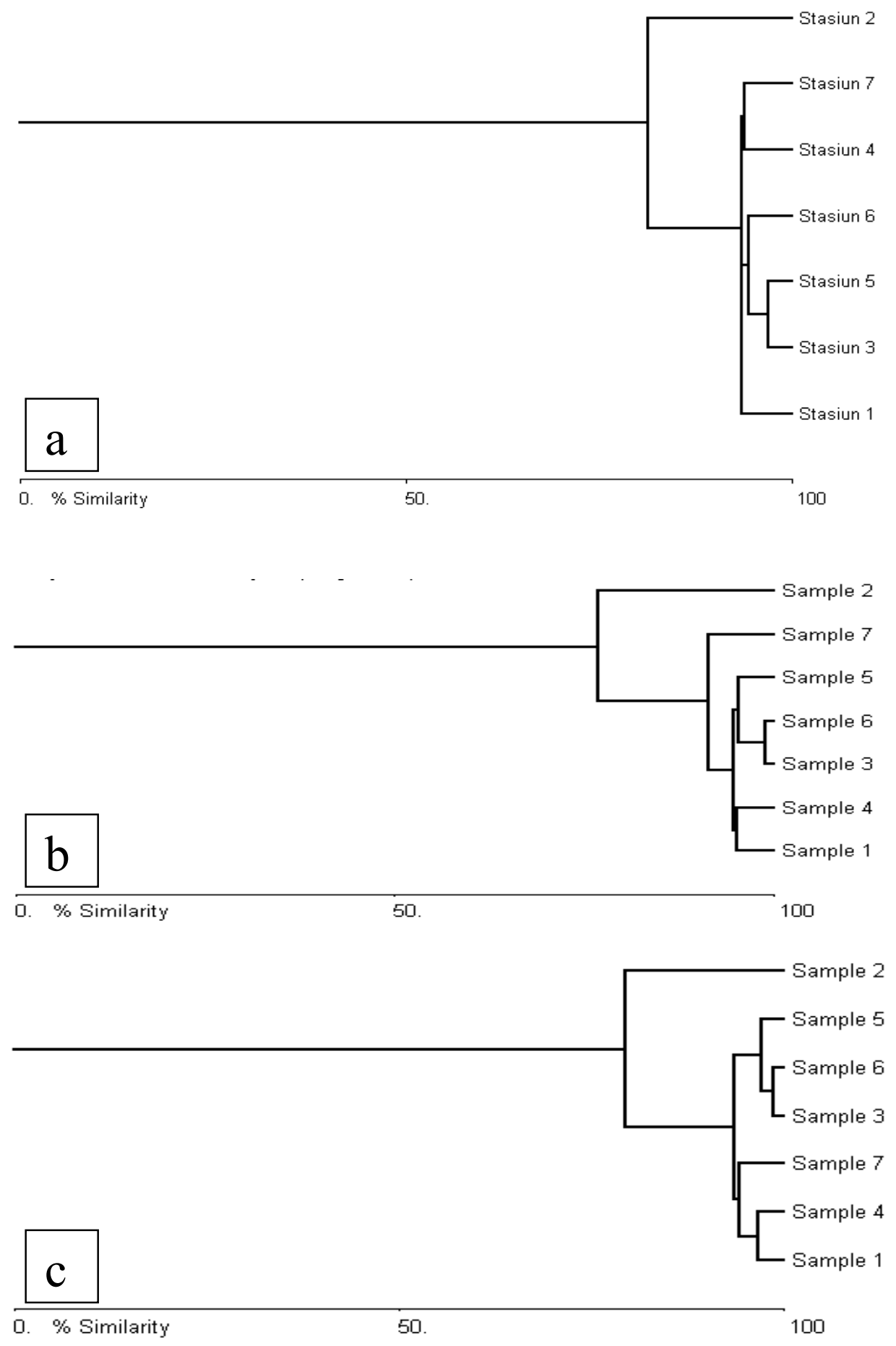
Gambar 2. Histogram yang menggambarkan persentase kesamaan antar stasiun: (a) untuk komunitas gabungan fitoplankton dan zooplankton (plankton), (b) untuk komunitas fitoplankton, dan (c) untuk komunitas zooplankton

Gambar 2 memperlihatkan, bahwa untuk komunitas plankton, stasiun III memiliki kesamaan dengan stasiun $\mathrm{V}$, stasiun IV dengan stasiun VII. Namun secara umum sesungguhnya ketujuh stasiun tersebut dikelompokkan menjadi dua, dimana stasiun II menjadi satu kelompok sendiri dan selebihnya menjadi kelompok tersendiri. Kelompok kedua yang terdiri dari 6 stasiun ini, kemudian terbagi menjadi 3 kelompok yang lebih kecil: pertama stasiun I menjadi kelompok sendiri; kedua staisun III, V dan VI menjadi satu kelompok; ketiga terdiri dari stasiun IV dan VIII. Sedangkan untuk komunitas fitoplankton, stasiun IV yang semula sama dengan stasiun VII, disini sama dengan stasiun I. Kemudian stasiun III berpasangan dengan staisun VI. Untuk komunitas zooplankton memperlihatkan stasiun VII berkecendrungan bekelompok dengan stasiun I dan IV.

Sementara itu, stasiun II mempunyai posisi tetap untuk ketiga komunitas tersebut. Kecendrungan ini, mungkin terjadi karena posisi stasiun II yang diapit oleh gili Ranggo dan daratan pantai Serewe menyebabkan stasiun tersebut lebih terlindung daripada stasiun lainnya. Stasiun II dan IV untuk komunitas fitoplankton dan zooplankton selalu bersamaan, dimana kedua stasiun ini berdekatan dengan daratan pantai teluk Serewe bagian timur. Artinya pengaruh daratan (terutama aliran bahan organik atau run-off) relatif sama terhadap kedua stasiun tersebut.

\section{Pembahasan}

Total komunitas plankton yang teridentifikasi dalam penelitian ini sebanyak 123 spesies meliputi, 82 spesies adalah plankton nabati (fitoplankton) dan sisanya, 41 spesies adalah plankton hewani (zooplankton). Jumlah jenis komunitas fitoplankton jauh lebih banyak dibandingkan dengan jumlah jenis zooplankton. Dominasi kelompok fitoplankton terhadap kelompok zooplankton merupakan suatu keadaan normal atau alami dalam ekosistem perairan. Sebagaimana diketahui, bahwa secara ekologis komunitas fitoplankton berperan sebagai produsen primer (menjadi dasar atau berada sebagai tropik paling dasar) dalam piramida rantai makanan ekosisten perairan. Sedangkan, komunitas zooplankton berada pada tropik kedua (sebagai konsumen tingkat pertama).

Dari 82 spesies komunitas fitoplankton yang berhasil diidentifikasi dalam penelitian, 75 spesies merupakan anggota dari famili Bacillariophyceae, dan hanya 7 spesies anggota dari famili Dinophyceae. Pada beberapa penelitian sebelumnya, yang dilakukan di sekitra perairan pantai pulau Lombok juga diperoleh hasil, bahwa anggota Bacillariophyceae selalu mendominasi Dinophyceae, seperti dilaporkan oleh: Japa (2000) di perairan pelabuhan Lembar, Lombok Barat; Feranita (2002), di perairan pelabuhan Kayangan, Lombok Timur; Japa dan Suripto (2003) di perairan Sambelia Lombok Timur; dan Sumarni (2003) di perairan Kerta Sari Taliwang, Sumbawa. Chaetoceros adalah komponen fitoplankton laut yang melimpah, tetapi karena jumlah spesiesnya yang sangat banyak maka rumit diidentifikasi (Hernandez-Becerril, 1996).

Komunitas fitoplankton perairan suaka perikanan gili Ranggo teluk Serewe Lombok Timur didominasi oleh genus Chaetoceros dengan lebih dari 19 spesies. Genus Chaetoceros juga diidentifikasi mendominasi jenis yang lain di perairan Lembar (Japa, 2000), di perairan Kerta Sari Sumbawa (Sumarni, 2003). Sedangkan komunitas zooplankton didominasi oleh 
genus Tintinnopsis dengan 16 spesies. Kemunculan genus Tintinnopsis jauh berbeda dengan genus Acartia yang dilaporkan sering melimpah $(80-90 \%$ total zooplankton) pada perairan dengan salinitas tinggi (Liang dan Uye, 1966, dalam Jufri et al., 1999). Nilai indeks keanekaragaman jenis (H') baik fitoplankton maupun zooplankton perairan suaka perikanan gili Ranggo teluk Serewe tergolong dalam kategori sedang (3,937 dan 2,542). Barus (2001) membagi kisaran nilai indeks keanekaragaman menjadi tiga kategori: a). Keanekaragaman rendah $\left(0<\mathrm{H}^{\prime}<2,302\right)$, b). Keanekaragaman sedang $\left(2,302<\mathrm{H}^{\prime}<\right.$ 6,907), dan c). Kenanekaragaman tinggi ( $\mathrm{H}^{\prime}$ $>6,907)$.

Secara kuantitatif, hubungan antara fitoplankton dan zooplankton suaka perikanan teluk Serewe Lombok Timur yang dihitung dengan rumus Korelasi Jenjang Spearman diperoleh hasil Korelasi Spearman pada taraf signifikansi $5 \%,\left(r_{S}\right)$ Hitung lebih kecil dari $r_{s}$ Tabel $(0,643<$ $0,857)$. Ini berarti tidak terdapat hubungan positif antara jumlah komunitas fitoplankton dan komunitas zooplankton pada perairan suaka perikanan tersebut. Kejadian seperti ini tidak bisa dijelaskan secara teoritis, tetapi sangat mungkin terjadi, mengingat pengambilan sampel dilakukan bersamaan pada siang hari. Zooplankton cendrung berada jauh di bawah permukaan air pada siang hari dan muncul pada malan harinya. Nybakken (1992) menjelaskan, pada siang hari zooplankton tidak berada di permukaan karena mereka memberikan tanggapan negatif terhadap cahaya matahari. Lampert dan Taylor (1985, dalam Wardhana, 1999) disebutkan, bahwa migrasi vertiael harian zooplankton terutama dipengaruhi oleh tingkah laku dan prevensi makan. Nybakken (1992) juga merincikan faktor migrasi vertikal zooplankton sebagai berikut: (1) strategi menghindari predator, (2) mengatur posisi dalam badan air, dan (3) strategi penghematan energi dan untuk bereproduksi.

\section{KESIMPULAN}

Kesimpulan yang bisa ditarik dari hasil penelitian ini, adalah: 1). Komunitas plankton perairan suaka perikanan gili Ranggo teluk Serewe Lombok Timur, yang berhasil diidentifikasi terdiri dari 123 spesies meliputi 82 fitoplankton dan 41 zooplankton. 2). Plankton, kelompok fitoplankton terdiri dari 75 spesies diatom (Bacillariophyceae), dan 7 spesies dinoflagellata (Dinophyceae). 3) Nitzschia longissima, Pseudo-nitzschia spp., dan Skeletonemma sp. adalah 4 spesies diatom yang dominan; dan Peridinium quinquecorne, Prorocentrum micans, dan Protoperidinium sp., adalah 3 spesies dinoflagellata yang memiliki dominasi paling besar. 4). Enam spesies zooplankton yang teridentifikasi dengan kepadatan dan nilai penting (NP) tertinggi berturut-turut adalah Tintinnopsis anguistor, T. radix, T., T. karajacensis, dan Acartia clausi. 5). Secara kuantitas, komunitas fitoplankton tidak memiliki korelasi positif terhadap komunitas zooplankton, dengan keanekaragaman masing-masing termasuk kategori sedang. 


\section{KEPUSTAKAAN}

Allen, W.E., and E.E. Cupp, 1935, Plankton Diatoms of the Java Sea, Annales $d u$ Jardin Botanique de Buitenzorg, 44: 101-174.

Arinardi, O.H., 1978, Hubungan antara Kuantitas Fitoplankton dan Zooplankton di Perairan Sebelah Utara Gugus Pulau Pari Kepulauan Seribu, Oseanologi di Indonesia, 11: 73-85.

Barus, I.T.A., 2001, Pengantar Limnologi, Direktorat Pembinaan Penelitian dan Pengabdian pada Masyarakat, Direktorat Jenderal Pendidikan Tinggi, Jakarta.

Belcher, J.H., and E.M.F. Swale, 1976, A Beginner's Guide to Freshwater Algae, Institude of Terrestrial Ecology Natural Environmental Research Council, Cambridge, London.

Cox, G.W., 1976, Laboratory Manual of General Ecology, W.M.C. Brown Co. Publisher, Iowa.

Dahuri, R., 2000, Kebijaksanaan Pengelolaan Sumberdaya Kelautan (Pesisir, Laut dan Pulau-Pulau Kecil), Makalah Konggres dan Seminar Kelautan Nasional KTI III, Lombok.

Feranita, 2002, Evaluasi Kandungan Nitrat, Fosfat dan Kelimpahan Fitoplankton di Perairan Pelabuhan Kayangan Lombok Timur, Skripsi, Prog. S1 Pend. Biologi, FKIP Universitas Mataram.

Hall, R.I. dan J.P. Smol, 1999, Diatoms as Indicators of Lake Eutrophication, di dalam E.F. Stoermer dan J.P. Smol (Editor), The Diatoms: Applications for the Environmental and Earth Sciences, Cambride University Press, United Kingdom.

Harder, D.P., R.C. Worrest, H.D. Kumar, and R.C. Smith, 1995, Effects of Increased Solar Ultraviolet Radiation on Aquatic Ecosystems, Ambio, 24(3): 174-180.
Hustedt, F., 1939, Systematic and Ecological Investigation of the Diatom Flora of Java, Bali, and Sumatra, Archive Für Hydrobiolgie, Suppl. 15: 131-177, 16: 1-155, 187-295, and 393506.

Hernandez-Becerril, D.U., 1996, A Morphological Study of Chaetoceros Species (Bacillariophyta) from the Plankton of the Pacific Ocean of Mexico, Bull. Nat. Hist. Mus. Lond. (Bot.), 26(1): 1-73.

Japa, L., 2000, Seasonal Succession of Phytoplankton Communities in Lombok Indonesian Coastal Waters, with Emphasis on Species of the Diatom Genera Pseudo-nitzshia and Thalassiosira, Thesis, Program Master, Universitas Tasmania.

Japa, L., dan Suripto, 2003, Inventarisasi Spesies Fitoplankton di Kawasan Perairan Budidaya Kerang Mutiara Dadap Sambelia Lombok Timur, Laporan Penelitian, Universitas Mataram, Mataram.

Jufri, A.W., A. Ramdani, dan Suripto, 1999, Identifikasi Jenis, Pola Distribusi dan Kelimpahan Zooplankton di Perairan Pulau Moyo Kabupaten Sumbawa, Laporan Penelitian, Universitas Mataram, Mataram.

Lebour, M.V., 1930, The Planktonic Diatoms of Northern Seas, Adlard and Son, Limited, London.

Michael, P., 1984, Ecology Methods for Field and Laboratory Investigations, Tata McGraw-Hill Publ. Co. Ltd., Toronto.

Navarro, J.N., 1982, A Survey of the Marine Diatoms of Puerto Rico III. Suborder Biddulphiineae: Family Chaetoceraceae, Botanica Marina, 25: 305-319.

Noor, A., 2000, Program Buginesia (Upaya Mengisi Matriks Pengetahuan Kelautan Indonesia) Dan Gagasan Pengembangan Riset Kelautan KTI, 
Makalah Konggres dan Seminar Kelautan Nasional KTI III, Lombok.

Nybakken, J.W., 1992, Biologi Laut: Suatu Pendekatan Ekologis, Terjemahan dari Marine Biology: An Ecological Approach oleh Eidman, M. Koesbiono, D.G. Dengen, M. Hutomo, dan S. Sukardjo, Gramedia, Jakarta.

Resosoedarmo, R.S., K. Kartawinata dan A. Soegiarto, 1992, Pengantar Ekologi, Remaja Rosdakarya, Bandung.

Romimohtarto, K. dan S. Juwana, 2001, Biologi Laut Ilmu Pengetahuan tentang Biota Laut, Djambatan, Jakarta.

Simonsen, R., 1974, The Diatom Plankton of the Indian Ocean Expedition of R/V 'Meteor" 1964-1965, "Meteor" Forsch.-Ergebnisse, Berlin Stuttgart, 19(D): 1-107.

Snedecor, G.W., dan Cochran, W.G., 1989, Statistical Methods, $8^{\text {th }}$ Eddition, Iowa State University Press, Ames, Iowa, USA.

Sprent, P., 1991, Metode Statistik Nonparametrik Terapan, Universitas Indonesia Press, Jakarta.

Sumarni, 2003, Keanekaragaman Jenis dan Kemelimpahan Bacillariophyta (Diatom) di Perairan Pantai Kerta Sari Taliwang Sumbawa, Skripsi, Prog. S1 Pend. Biologi, FKIP Universitas Mataram.

Taylor, F.J.R., 1976, Dinoflagellates from the International Indian Ocean Expedition: A Report on Material Collected by the R.V. "Anton Bruun" 1963-1964, Stuttgart, E. Schweizerbart'sche Verlagsbuchhandlung (Nagele u. Obermiller).

Vinyard, W.C., 1979, Diatoms of North America, Mad River Press, Inc., California.

Wardhana, W., 1999, Hubungan Kuantitas antara Fitoplankton dan Zooplankton di Perairan Laut, Sungai, dan Situ,
Lingkungan Pembangunan, 19(2): 136-148.

Yamaji, I., 1984, Illustrations of The Marine Plankton of Japan, $3^{\text {rd }}$. Eddition, Hoikusha Publishing Co., Ltd., Japan. 